\title{
Osteoarticular melioidosis: a retrospective cohort study of a neglected disease
}

\author{
Nitin Gupta ${ }^{1,2}$, Shyamasunder N. Bhat ${ }^{3}$, Suhas Reddysetti ${ }^{4}$, Rajagopal Kadavigere ${ }^{5}$, \\ Vishwapriya M. Godkhindi ${ }^{6}$, Chiranjay Mukhopadhyay ${ }^{7}$, Kavitha Saravu'1,2 \\ ${ }^{1}$ Department of Infectious Diseases, Kasturba Medical College and Hospital, Manipal, Manipal Academy of Higher \\ Education, Manipal, Karnataka, India; \\ ${ }^{2}$ Manipal Center for Infectious Diseases, Prasanna School of Public Health, Manipal Academy of Higher Education, \\ Manipal, Karnataka, India; \\ ${ }^{3}$ Department of Orthopaedics, Kasturba Medical College and Hospital, Manipal, Manipal Academy of Higher \\ Education, Manipal, Karnataka, India; \\ ${ }^{4}$ Department of Medicine, Kasturba Medical College and Hospital, Manipal, Manipal Academy of Higher \\ Education, Manipal, Karnataka, India; \\ ${ }^{5}$ Department of Radiodiagnosis, Kasturba Medical College and Hospital, Manipal, Manipal Academy of Higher \\ Education, Manipal, Karnataka, India; \\ ${ }^{6}$ Department of Pathology, Kasturba Medical College, Manipal, Manipal Academy of Higher Education, \\ Manipal, Karnataka, India; \\ ${ }^{7}$ Department of Microbiology, Kasturba Medical College and Centre for Emerging and Tropical Diseases, \\ Manipal, Manipal Academy of Higher Education, Manipal, Karnataka, India
}

Article received 11 August, 2021; accepted 5 October, 2021

\section{SUMMARY}

Introduction: Patients with melioidosis can present with a combination of fever, respiratory distress and focal involvement. Focal involvement of bone and joint is, however, rare in patients with melioidosis. This study aimed to characterize patients with osteoarticular melioidosis. Patients and Methods: This was a retrospective review of records of all adult patients diagnosed with culture-positive osteoarticular melioidosis over three years. The clinical, laboratory and treatment details were recorded in a predefined case-record form and analyzed. Results: Of the 11 patients with osteoarticular melioidosis, $55 \%(n=6)$ had concurrent pulmonary involvement. The patients were classified as isolated osteomyelitis $(n=3)$, isolated arthritis $(n=3)$, and both osteomyelitis and septic arthritis $(n=5)$. Of eight patients with joint involvement, $87.5 \%$ had monoarthritis. A single bone was involved in $75 \%$ of the patients with bone involvement $(n=8)$. Concomitant myositis was seen in $36.4 \%(n=4)$ of the cases. Local debridement of the involved bone or joint was done in $54.5 \%(n=6)$ of the cases. Combination therapy with ceftazidime/meropenem and cotrimoxazole was predominantly used as intensive therapy for a mean of $3 \pm 1.3$ weeks. Monotherapy with cotrimoxazole was used as eradication therapy for a mean of $4.6 \pm 2$ months. Except for one patient with recurrent disease and one death, all patients were declared cured at the end of therapy. Conclusion: Osteoarticular melioidosis should be suspected in high-risk individuals from endemic areas with single bone or joint involvement and surrounding myositis. Early diagnosis and prompt initiation of therapy is key to a favourable response.

Keywords: Burkholderia pseudomallei, osteomyelitis, septic arthritis.
Corresponding author

Kavitha Saravu

E-mail: kavithasaravu@gmail.com

\section{INTRODUCTION}

Rurkholderia pseudomallei is a Gram-negative, $B$ facultative, intracellular bacteria that causes a multisystem disease called melioidosis [1]. It must be noted that it is distinctly different from another member of the same genus, B. cepacia, which is 
an organism of low virulence and causes nosocomial infections, especially in children with cystic fibrosis [2,3]. Melioidosis is endemic in parts of Australia and Asia (including India), where the bacterium exists in the soil and surface water [1]. It is transmitted to humans predominantly by the percutaneous inoculation and inhalation route. However, it can also be transmitted by aspiration or ingestion as well [1]. The patients can present with a combination of fever, respiratory distress and hypotension or with symptoms of focal involvement like skin/soft tissue infection or abscesses in visceral organs [1]. Osteomyelitis and septic arthritis are uncommon complications of patients with melioidosis. In a 30-year prospective study designed to study epidemiology (The Darwin Prospective Melioidosis study), of the 1148 patients with melioidosis, osteomyelitis and septic arthritis was seen in 1\% and 3\% of the cases, respectively [1]. Although rare, it is important to suspect osteoarticular melioidosis early as it is not covered by most empiric regimens and is associated with debilitating complications in the absence of adequate therapy. This study, therefore, aimed to characterize patients of melioidosis with bone and joint involvement.

\section{PATIENTS AND METHODS}

This was a retrospective review of records of all adult patients diagnosed with osteoarticular infections between 2018 and 2020 after approval from the Institute's Ethics Committee. The study was conducted in a teaching tertiary care hospital located in the coastal district (Udupi) of Karnataka (South India). The records of all cases with osteoarticular involvement in this period were screened for a possible diagnosis of melioidosis. A case was diagnosed as osteoarticular melioidosis if there were clinical features of osteoarticular involvement along with the isolation of B. pseudomallei in culture. The patients were categorized into acute $(<2$ months duration of illness) or chronic ( $>2$ months duration of illness) based on their duration of illness at presentation. The following details were recorded in a predefined case-record form: demography, comorbidities, the pattern of osteoarticular involvement, systemic manifestations, laboratory parameters, microbiological tests and treatment (both surgical and medical). The patients were classified into: isolat- ed osteomyelitis, isolated septic arthritis or both. The treating physician decided the intensive and eradication therapy duration based on the clinical response and trend of erythrocyte sedimentation rate (ESR), C-reactive protein (CRP), and procalcitonin. The outcome of all patients at the end of the eradication therapy was also recorded. Those patients with significant clinical and radiological improvement at discontinuation of medication were defined as 'cured'. Those patients who presented with recurrence of diseases after completion of intensive phase were characterized as recurrent disease. The findings were entered in an excel workbook, and the final analysis was done after anonymizing potential identifiers.

\section{RESULTS}

Eleven patients of culture-confirmed melioidosis were included in this study. Of the 11 patients, nine were men. The mean age of the patients was $49.8 \pm 12.2$ years (Table 1 ). All the patients hailed from either of the four districts of Karnataka: Udupi $(n=8)$, Shimoga $(n=1)$, Davangere $(n=1)$ and Uttara Kannada $(n=1)$. Of the 11 patients, 55\% $(n=6)$ worked as farmers, and one was a fisherman. Others were involved in farming activities to some degree as well. A total of $82 \%(n=9)$ patients had diabetes mellitus (DM) with a mean glycosylated haemoglobin value of $10.4 \pm 2 \mathrm{~g} / \mathrm{dl}$. Additionally, two patients had a prior history of trauma to the affected bone or joint.

All the patients had an acute disease at the first presentation with $21.5 \pm 10.5$ days as the mean duration of symptoms at presentation (Table 1). A history of fever was present in $55 \%(n=6)$ of the patients, but shock and Acute Kidney Injury (AKI) were observed in $9 \%(n=1)$ and $27.3 \%(n=3)$ of the patients.

Isolated osteoarticular melioidosis was reported in $45.5 \%(n=5)$ of the patients, while concurrent pulmonary involvement was seen in $55 \%(n=6)$ of the patients (Table 1). Isolated osteomyelitis was noted in three patients, whereas five patients had both osteomyelitis and septic arthritis. Three patients were reported to have isolated arthritis (Figures 1-3). Monoarticular involvement was seen in $87.5 \%$ of patients with joint involvement $(n=8)$, while single bone osteomyelitis was noted in $75 \%$ of the patients with bone involvement $(n=8)$. Concomitant myositis was seen in $36.4 \%(n=4)$ of 
Table 1 - Demography and clinical profile of patients diagnosed with osteoarticular melioidosis.

\begin{tabular}{|c|c|c|c|c|c|c|c|c|c|}
\hline Sn & $\begin{array}{l}\text { Month of } \\
\text { presentation }\end{array}$ & Occupation & $\begin{array}{l}\text { District } \\
\text { of residence }\end{array}$ & Comorbidity & $\begin{array}{l}\text { Duration } \\
\text { of illness at } \\
\text { presentation } \\
\text { (in days) }\end{array}$ & Fever & Shock & Pulmonary & $\begin{array}{l}\text { Acute } \\
\text { Kidney } \\
\text { Injury }\end{array}$ \\
\hline 1 & August & Farmer & Udupi & $\mathrm{DM}(7.2)$ & 25 & & & & \\
\hline 2 & July & Carpenter & Udupi & DM (10.9), alcohol & 25 & Yes & & Yes & \\
\hline 3 & July & Farmer & Shimoga & DM (12.8), trauma & 2 & & Yes & Yes & Yes \\
\hline 4 & November & Farmer & Davangere & $\begin{array}{c}\text { DM (10.3), } \\
\text { COPD, alcohol, } \\
\text { inhaled steroids }\end{array}$ & 30 & & & Yes & Yes \\
\hline 5 & August & Driver & Udupi & $\mathrm{DM}(12.3)$ & 15 & Yes & & & \\
\hline 6 & July & Student & Udupi & Trauma & 8 & Yes & & & \\
\hline 7 & August & House wife & Udupi & $\begin{array}{c}\text { DM (8.2), } \\
\text { KTP, steroids }\end{array}$ & 5 & Yes & & & \\
\hline 8 & July & Farmer & Udupi & DM (11.7) & 7 & Yes & & Yes & Yes \\
\hline 9 & August & Fisherman & Udupi & $\begin{array}{l}\text { DM (7), post- } \\
\text { COVID, steroids }\end{array}$ & 15 & & & Yes & \\
\hline 10 & December & House-wife & Udupi & $\begin{array}{c}\text { Alternative } \\
\text { medications } \\
\text { (Details unknown) }\end{array}$ & 20 & Yes & & Yes & \\
\hline 11 & July & Farmer & $\begin{array}{c}\text { Uttar } \\
\text { Kannada }\end{array}$ & DM (13) & 21 & & & & \\
\hline
\end{tabular}

*Abbreviation: $\mathrm{Sn}=$ Serial number; DM = diabetes mellitus with glycosylated haemoglobin (\%) in brackets, KTP = post-kidney transplant; COVID = Coronavirus disease 2019.

the cases. The details of joint involvement have been summarised in Table 2. Hepatomegaly was present in three patients, while splenomegaly was noted in two patients. Leukocytosis and thrombocytopenia were seen in 55\% $(n=6)$ and $36.4 \%(n=4)$ patients respectively (Table 3 ). CRP, procalcitonin and ESR were elevated in all the patients where they were done (Table 3). Blood and pus culture were positive for B. pseudomallei in 89\% (8/9) and $100 \%(8 / 8)$ patients, respectively (Table 3). All the culture isolates were sensitive to meropenem, ceftazidime and cotrimoxazole.

Local debridement of the involved bone or joint was done in $54.5 \%(n=6)$ of the cases (Table 4$)$.

Figure 1 A, B - Fat-suppressed proton-density MRI shows features of osteomyelitis of ulna (long arrow), elbow joint septic arthritis (arrow head) and myositis of adjacent muscles (small arrow).
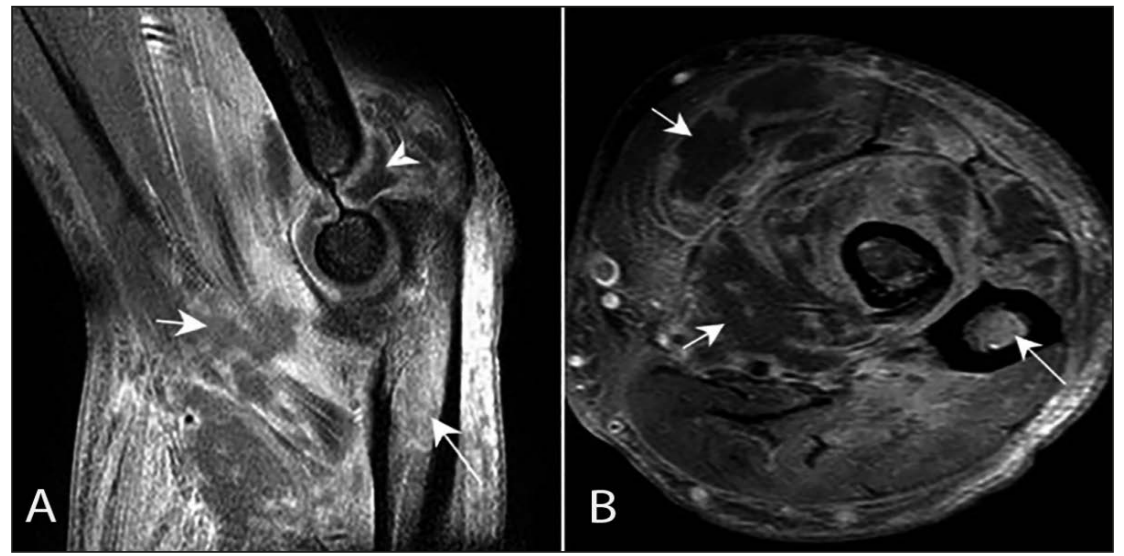


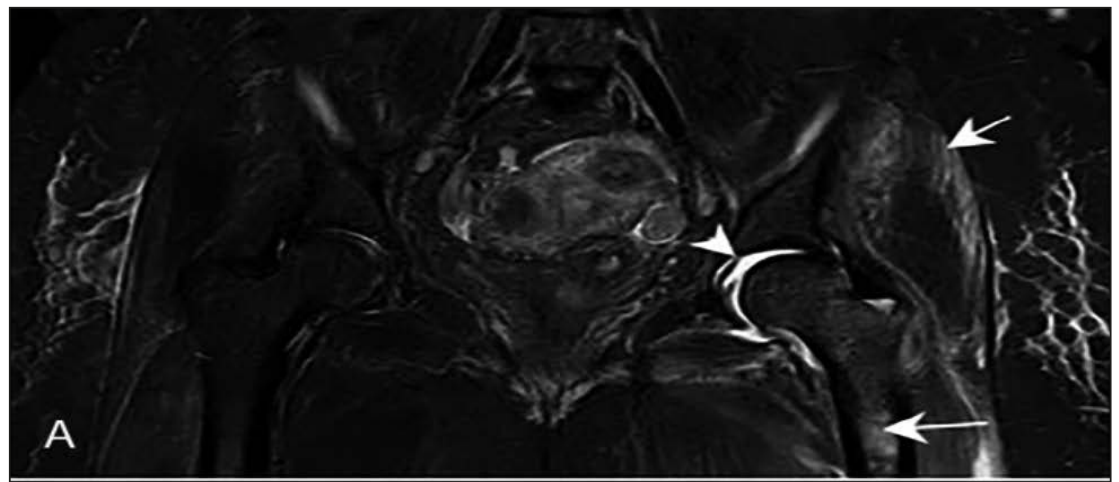

Figure 2 A, B - STIR MRI sequence shows features of left femoral osteomyelitis (long arrow), minimal left hip joint effusion (arrow head) and myositis (small arrow).

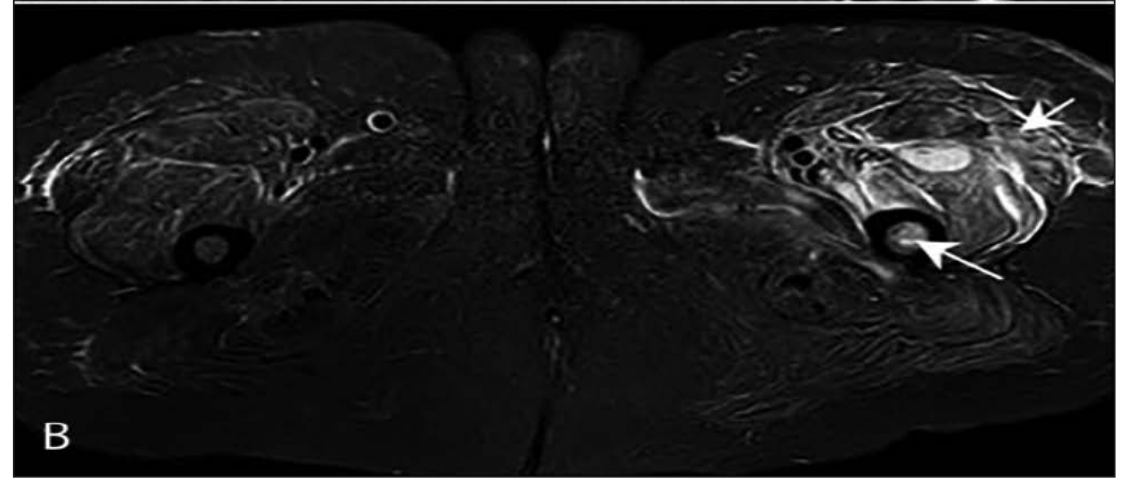

Figure 3 A, B - STIR MRI se-

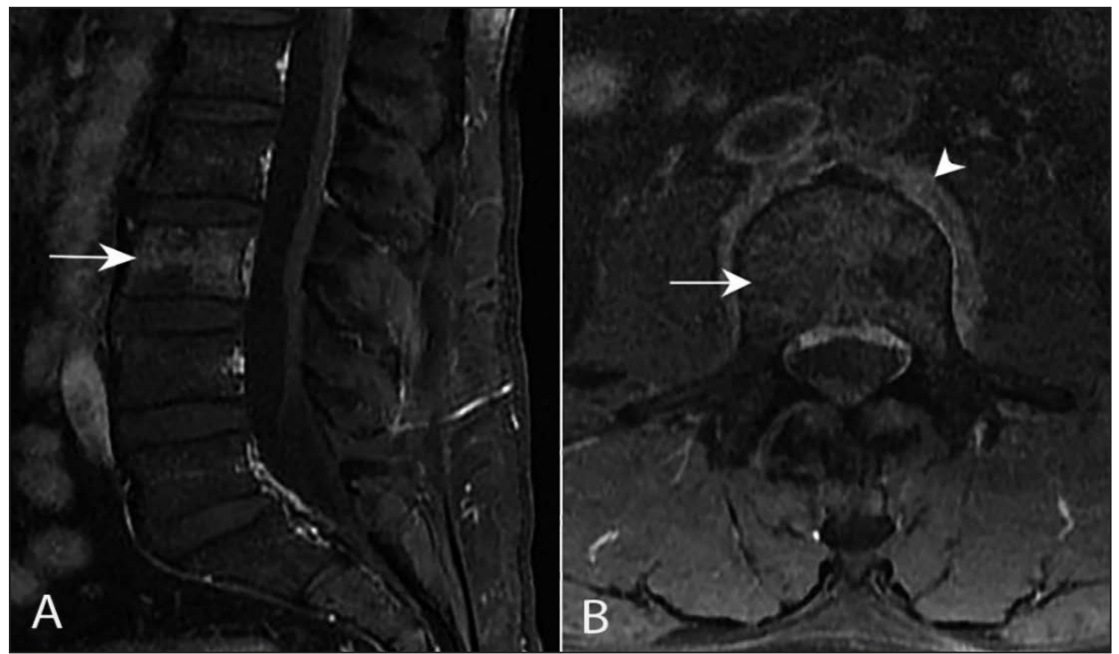
quence shows spondylitis involving the L3 vertebral body (arrow), with prevertebral and paravertebral soft tissue components (arrow head).

Histopathological examination of the debrided tissues was done in four patients (Cases 1, 2, 5, $6)$, where it revealed mixed inflammatory infiltrate and necrotic debris (Figures 4, 5 and 6). During the intensive therapy, except for $18.2 \%$ $(n=2)$ of the patients who received monotherapy with intravenous (IV) meropenem (25-50 mg/ kg every eight hours), all patients received combination therapy (Table 4). Combination therapy of IV meropenem and oral cotrimoxazole (double strength tablets twice daily) was given to $63.6 \%(n=7)$ of the patients. In comparison, $18.2 \%(n=2)$ of the patients received a combination of IV ceftazidime $(50 \mathrm{mg} / \mathrm{kg}$ every eight 
Table 2 - Clinical or radiological involvement of bone, joints and muscles in patients with melioidosis.

\begin{tabular}{|c|c|c|c|c|c|c|}
\hline Sn & $\begin{array}{l}\text { Number of } \\
\text { involved bones }\end{array}$ & Bones involved & $\begin{array}{c}\text { Number of joints } \\
\text { involved }\end{array}$ & Joints involved & Myositis & $\begin{array}{c}\text { Intramuscular } \\
\text { collections }\end{array}$ \\
\hline 1 & 1 & U/L humerus & 1 & U/L elbow & Yes & \\
\hline 2 & 3 & $\begin{array}{l}\mathrm{U} / \mathrm{L} \text { humerus, } \\
\text { radius, ulna }\end{array}$ & 1 & U/L elbow & Yes & Yes \\
\hline 3 & 0 & & 1 & U/L knee & Yes & \\
\hline 4 & 1 & U/L Tibia & 1 & U/L knee & & \\
\hline 5 & 1 & U/L Clavicle & 0 & & & \\
\hline 6 & 2 & U/L Tibia, Femur & 1 & $\mathrm{U} / \mathrm{L}$ knee & & \\
\hline 7 & 1 & Skull & 0 & & & \\
\hline 8 & 1 & L3 vertebrae & 0 & & & \\
\hline 9 & 1 & U/L Clavicle & 1 & $\begin{array}{c}\text { U/L sternoclavicular } \\
\text { joint }\end{array}$ & & \\
\hline 10 & 0 & & 3 & U/L hip, knee, ankle & Yes & \\
\hline 11 & 0 & & 1 & $\mathrm{U} / \mathrm{L}$ ankle & & \\
\hline
\end{tabular}

Abbreviation: $\mathrm{Sn}=$ Serial number, $\mathrm{U} / \mathrm{L}=$ unilateral

Table 3 - Laboratory parameters of patients with osteoarticular melioidosis.

\begin{tabular}{|c|c|c|c|c|c|c|c|}
\hline$S n$ & $\begin{array}{c}\text { TLC } \\
\left(10^{3} / \mu l\right)\end{array}$ & $\begin{array}{l}\text { Platelet } \\
\left(10^{5} / \mu l\right)\end{array}$ & $\begin{array}{c}\text { CRP } \\
(m g / d l)\end{array}$ & $\begin{array}{c}\text { ESR } \\
\text { (mm/hour) }\end{array}$ & $\begin{array}{c}P C T \\
(n g / m l)\end{array}$ & $\begin{array}{c}\text { Blood culture } \\
\text { positivity }\end{array}$ & $\begin{array}{l}\text { Pus culture } \\
\text { positivity }\end{array}$ \\
\hline 1 & 8.2 & 3.2 & 143 & 49 & & & Yes \\
\hline 2 & 18.3 & 3.3 & 301 & 120 & & Yes & Yes \\
\hline 3 & 14.8 & 1.2 & 259 & 28 & 73 & Yes & Yes \\
\hline 4 & 14 & 2.5 & & 88 & 8 & Yes & Yes \\
\hline 5 & 13.9 & 3.6 & & 75 & & & Yes \\
\hline 6 & 18.7 & 4.5 & & & & Yes & Yes \\
\hline 7 & 10 & 3.1 & 165 & 22 & & & Yes \\
\hline 8 & 6.1 & 1.2 & & 44 & 106 & Yes & \\
\hline 9 & 4 & 1.3 & 24 & 35 & & Yes & \\
\hline 10 & 13.8 & 1.1 & 221 & 51 & 4 & Yes & Yes \\
\hline 11 & 7.3 & 3.2 & 123 & 47 & 3 & Yes & \\
\hline
\end{tabular}

Abbreviation: $\mathrm{Sn}$ : $=$ Serial number, $\mathrm{TLC}=$ total leucocyte count, $\mathrm{CRP}=\mathrm{C}$-reactive protein, $\mathrm{ESR}=$ Erythrocyte sedimentation rate, $\mathrm{PCT}=$ procalcitonin.

hours) and oral cotrimoxazole (double strength tablets twice daily) (Table 4). The intensive therapy was given for a varying duration of 2-6 weeks with a mean of $3 \pm 1.3$ weeks (Table 4 ). All patients received eradication therapy with oral cotrimoxazole (double strength tablets twice daily) for a varying duration of 1-7 months with a mean of $4.6+2$ months (Table 4 ). One patient stopped the eradication therapy after one month and was declared as a loss to follow-up. He presented again with symptoms five months later. This second presentation was treated with IV ceftazidime + oral cotrimoxazole for six weeks, followed by oral cotrimoxazole for 12 months. One patient died after he left against medical advice during intensive therapy. All other patients were reported to be cured at the end of the eradication therapy. 
Table 4 - Details of treatment and outcome of patients with osteoarticular melioidosis.

\begin{tabular}{|c|c|c|c|c|c|c|}
\hline Sn & $\begin{array}{l}\text { Surgical } \\
\text { procedure }\end{array}$ & Intensive therapy (IT) & $\begin{array}{l}\text { Duration of } \\
\text { IT (weeks) }\end{array}$ & $\begin{array}{c}\text { Eradication therapy } \\
\text { (ET) }\end{array}$ & $\begin{array}{l}\text { Duration of } \\
\text { ET (months) }\end{array}$ & Outcome \\
\hline 1 & $\begin{array}{c}\text { Local } \\
\text { debridement }\end{array}$ & Meropenem & 2 & Cotrimoxazole & 3 & Cured \\
\hline 2 & $\begin{array}{c}\text { Local } \\
\text { debridement }\end{array}$ & Meropenem & 2 & Cotrimoxazole & 3 & Cured \\
\hline 3 & $\begin{array}{l}\text { Diagnostic } \\
\text { aspiration }\end{array}$ & $\begin{aligned} & \text { Ceftazidime } \\
+ & \text { Cotrimoxazole }\end{aligned}$ & 2 & - & - & Death \\
\hline 4 & $\begin{array}{c}\text { Local } \\
\text { debridement }\end{array}$ & $\begin{array}{l}\text { Meropenem + cotrimoxazole } \\
\text { for } 10 \text { days } \mathrm{f} / \mathrm{b} \text { Ceftazidime } \\
\text { plus cotrimoxazole }\end{array}$ & 4 & Cotrimoxazole & 7 & Cured \\
\hline 5 & $\begin{array}{c}\text { Local } \\
\text { debridement }\end{array}$ & Meropenem + cotrimoxazole & 2 & Cotrimoxazole & 6 & Cured \\
\hline 6 & $\begin{array}{c}\text { Local } \\
\text { debridement }\end{array}$ & Meropenem + cotrimoxazole & 6 & Cotrimoxazole & 1 & $\begin{array}{l}\text { Loss to } \\
\text { follow-up* }\end{array}$ \\
\hline 7 & $\begin{array}{c}\text { Local } \\
\text { debridement }\end{array}$ & Meropenem + cotrimoxazole & 2 & Cotrimoxazole & 5 & Cured \\
\hline 8 & & Meropenem + cotrimoxazole & 4 & Cotrimoxazole & 6 & Cured \\
\hline 9 & & $\begin{array}{c}\text { Meropenem + cotrimoxazole } \\
\text { for } 10 \text { days } \mathrm{f} / \mathrm{b} \text { Ceftazidime } \\
\text { plus cotrimoxazole }\end{array}$ & 3 & Cotrimoxazole & 6 & Cured \\
\hline 10 & $\begin{array}{l}\text { Diagnostic } \\
\text { aspiration }\end{array}$ & $\begin{array}{c}\text { Meropenem + cotrimoxazole } \\
\text { for } 21 \text { days f/b Ceftazidime } \\
\text { plus cotrimoxazole }\end{array}$ & 4 & Cotrimoxazole & 3 & Cured \\
\hline 11 & & Ceftazidime + cotrimoxazole & 2 & Cotrimoxazole & 6 & Cured \\
\hline
\end{tabular}

Abbreviations: $\mathrm{Sn}=$ Serial number, IT = Intensive therapy, ET = Eradication therapy, $\mathrm{f} / \mathrm{b}=$ Followed by

*Second presentation was treated with ceftazidime + cotrimoxazole for six weeks, followed by cotrimoxazole for 12 months.

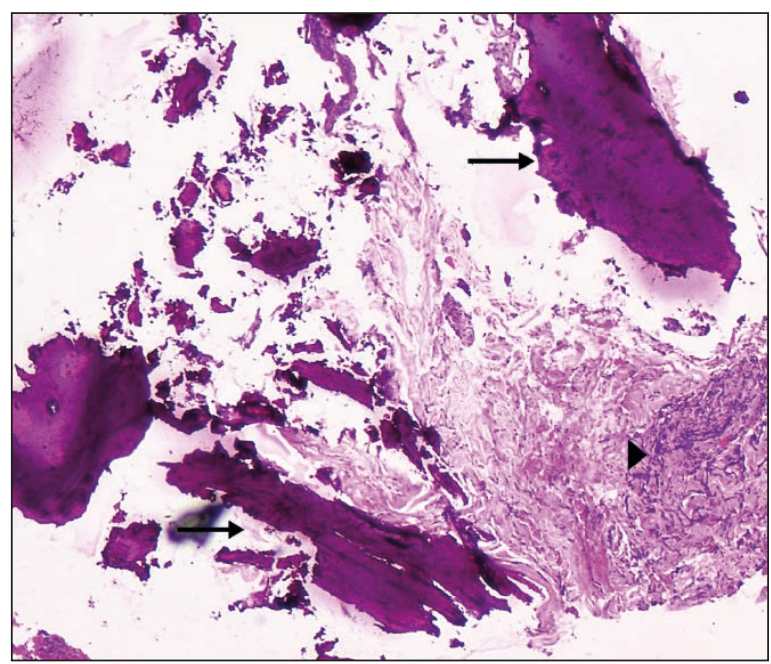

Figure 4 - Sections studied show fragments of dead bone (arrow) along with inflammatory aggregates composed of neutrophils, Iymphocytes, along with inflamed fibrocollagenous granulation tissue (arrow head).

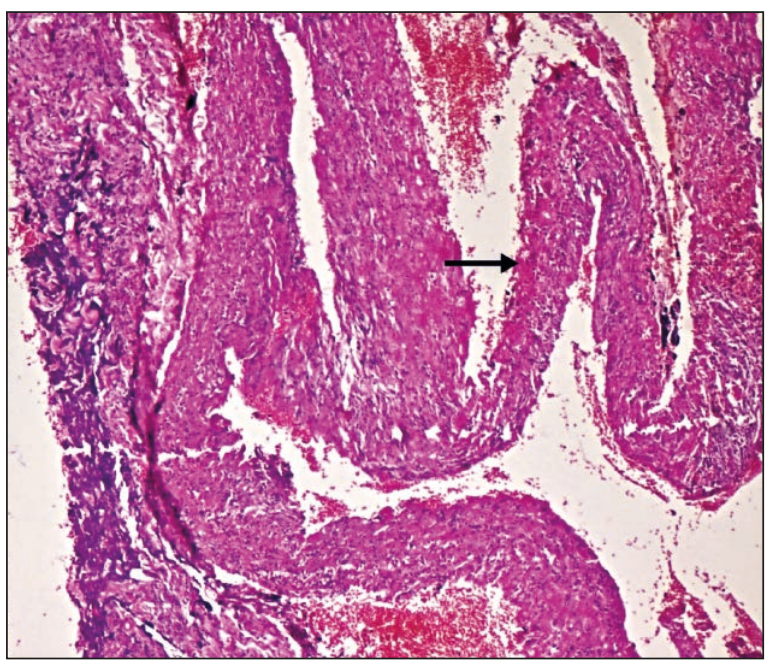

Figure 5 - Inflamed denuded synovium (arrow) with dense mixed inflammatory infiltrate with necroinflammatory debris. 


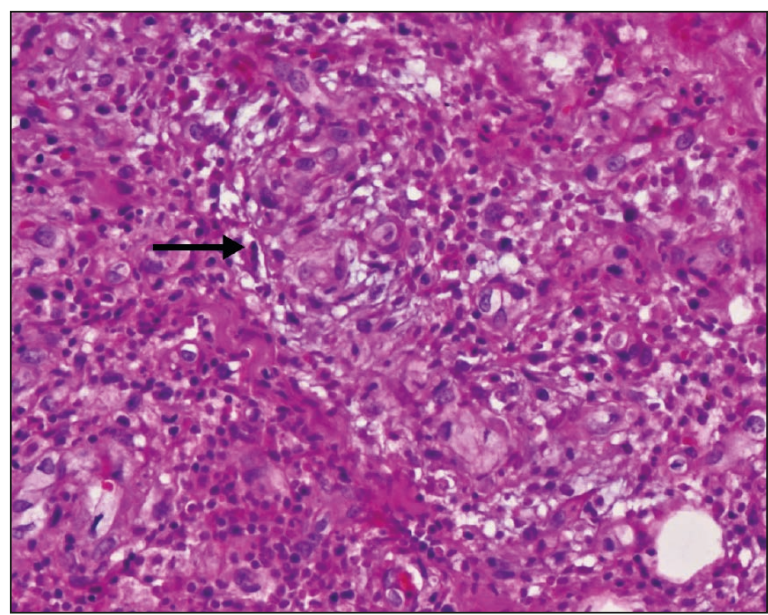

Figure 6 - Sections studied show aggregates of histiocytes \& macrophages, at places forming ill-formed non-caseating granulomas (arrow).

\section{DISCUSSION}

In this series, we report eleven cases of osteoarticular melioidosis. Like our series, most patients with melioidosis (including osteoarticular) present in the acute phase [1]. In a series of 21 patients with osteoarticular melioidosis, the mean duration of symptoms at presentation was 37 days compared to 21 days in our series [4]. A definite gender predilection was observed in our series, with most patients being males. This is similar to other reports in published literature and has been attributed to increased work-related exposure to soil [1,4-6]. Most patients in our series were either farmer or were involved in occasional farming activities. Since the bacterium is commonly found in the soil, most patients have a history of farming [1].

Pulmonary involvement is the commonest presentation as inhalation is one of the most common routes $[1,7]$. In a study from Thailand, concurrent pulmonary involvement was more common in patients with septic arthritis related to melioidosis [8]. In our study, 55\% $(n=6)$ of patients had simultaneous pulmonary involvement. The presentation of $82 \%(n=9)$ of the patients coincided with the onset of monsoons in this region (July, August). Previous studies have shown that heavy rainfall and storms can predispose to an increase in the number of cases of melioidosis in endemic areas [7]. In the Darwin study, DM was seen in $45 \%$ of all patients with melioidosis [1]. The pro- portion of diabetic individuals in those with osteoarticular melioidosis has been reported to be even higher. Similar to our study, many studies in published literature have reported the prevalence of DM to be more than $80 \%$ in those with osteoarticular melioidosis $[5,6,8]$. In the study on osteoarticular melioidosis by Shetty et al., the presence of diabetes was associated with multi-focal presentation and higher rates of complication [9]. Other risk factors for osteoarticular melioidosis include heavy alcohol use, chronic kidney disease, chronic lung disease, malignancy, and the use of immunosuppressive agents (including steroids) [5]. Two patients had a history of systemic steroid use in our study, while one was receiving inhaled steroids. In general, the incubation period following exposure ranges from 1 to 21 days (mean nine days). However, cases have been reported in individuals after decades of suspected exposure during the visit to an endemic area. In our series, a fisherman was initially admitted with fever and respiratory distress and was diagnosed with severe COVID-19 based on a polymerase chain reaction assay of the nasopharyngeal swab. He did not have any osteoarticular involvement at presentation, and the initial blood culture was negative. The patient was managed with awake proning and oxygen through nasal prongs. He also received steroids for $>10$ days and showed significant improvement. However, he developed a recurrence of fever in-hospital after ten days of admission with focal clavicular involvement. Repeated blood culture at this time was positive for melioidosis. Although it is possible that he might be in incubation at the time of presentation, it could have been due to a possible reactivation of latent bacilli acquired because of his frequent exposure to water. Local trauma to the clavicle (during prolonged awake proning) and intake of high dose steroids may have further accentuated the reactivation process. It must be noted that the frequency of cases with reactivation is much lower when compared to new infections [1].

Apart from the inhalation route where the organism can be disseminated hematogenously to bone/joints, direct inoculation from abrasion or trauma is the other common route of bone/joint involvement [10]. In our series, the history of trauma was noted in $18 \%$ of the patients. Monoarthritis is more common than oligo/polyarthritis in patients with melioidosis [6]. Of eight pa- 
tients with joint involvement, $87.5 \%(n=7)$ had monoarthritis in our series. Four patients in this series also showed features of myositis, which is not described commonly with other causes of osteomyelitis (Figure 1,2). Joint involvement along with bone and muscle involvement should raise the suspicion of melioidosis as one of the differentials. Of eight patients with bone involvement, a single bone was involved in $75 \%(n=6)$ of the patients. The most involved bones in our series were the humerus and tibia. In a review by Raja et al., lower extremity large bones and joints were more commonly involved in patients with osteoarticular melioidosis [10]. In a series of 44 patients by $\mathrm{Wu}$ et al., the involvement of knee joint and the femur was relatively more common [5]. On the contrary, in a retrospective case-control study of patients with septic arthritis, upper extremity involvement was more common in those with melioidosis when compared to other causes [11]. In a series of 50 patients with osteoarticular melioidosis by Shetty et al., adjacent bone involvement in patients with septic arthritis was seen in $22 \%(n=11)$ patients [9]. Similarly to our series, increased WBC count, CRP, ESR and procalcitonin have been commonly described in patients with melioidosis [10].

The definite diagnosis of melioidosis requires culture from blood or body fluids. Confirmation can be done by phenotypic or genotypic methods. $B$. pseudomallei is sensitive to amoxicillin-clavulanic acid and intrinsically resistant to penicillin, the first two generations of cephalosporins, colistin and aminoglycosides. While resistance can be seen uncommonly with ceftazidime, resistance to carbapenems and cotrimoxazole has not been reported. No resistance was reported in our series. For non-critically ill patients, ceftazidime is the choice of initial intensive therapy. In those with critical illness or CNS involvement, meropenem may serve as a better choice. Those patients who improve with meropenem can be switched to ceftazidime to complete the duration of initial intensive therapy. The addition of cotrimoxazole to meropenem or ceftazidime is suggested for patients with bone or joint involvement, owing to its excellent tissue penetration and intracellular activity. The duration of intensive treatment ranges from two weeks in non-critical patients to 4-8 weeks in critically ill patients or those with CNS or osteoarticular involvement. Intensive therapy should be followed by eradication therapy with oral cotrimoxazole. This is necessary to avoid recurrence. One patient with a possible recurrence in our series stopped eradication therapy after one month, which could have been the primary reason for recurrent disease. The duration of the eradication therapy ranges from three months in non-critically ill to six months in those with CNS or osteoarticular involvement. Severe disease, involvement of multiple sites, positive blood cultures and poor compliance are risk factors for recurrence [9]. Treatment of recurrence usually requires re-initiation of intensive therapy, followed by eradication therapy. Severe disease manifestations like shock are relatively less common in bone/joint melioidosis [10]. In our study, only one patient was found to be in septic shock at presentation. Incidentally, this patient did not complete the intensive therapy and left the hospital against medical advice. He died shortly after. No other deaths were reported in our series. In a study of 536 patients from Darwin, mortality was $5 \%$ in 41 patients with osteoarticular melioidosis compared to $14 \%$ in 495 patients with melioidosis elsewhere [12]. It must be noted that the mortality in osteoarticular melioidosis is significantly lesser when compared to other presentations of melioidosis [8]. However, the mortality with osteoarticular melioidosis is still higher when compared to other causes of septic arthritis [8].

In conclusion, osteoarticular melioidosis should be suspected in diabetic individuals with a history of exposure and acute onset osteomyelitis or septic arthritis of large bone/joints. Associated myositis should alert the possibility of melioidosis. Early and prompt initiation of medical therapy for appropriate duration is associated with good response.

\section{Conflicts of interest \\ None.}

\section{Funding}

None.

\section{REFERENCES}

[1] Currie BJ, Mayo M, Ward LM, et al. The Darwin Prospective Melioidosis Study: a 30-year prospective, observational investigation. Lancet Infect Dis. 2021; S14733099(21)00022-0. 
[2] Viderman Dy, Khudaibergenova M, Kemaikin V, Zhumadilov A, Poddighe D. Outbreak of catheterrelated Burkholderia cepacia sepsis acquired from contaminated ultrasonography gel: the importance of strengthening hospital infection control measures in low resourced settings. Infez Med. 2020; 4, 551-7.

[3] Abdallah M, Abdallah HA, Memish ZA. Burkholderia cepacia complex outbreaks among non-cystic fibrosis patients in the intensive care units: A review of adult and pediatric literature. Infez Med. 2018; 4, 299-307.

[4] Kosuwon W, Saengnipanthkul S, Mahaisavariya B, Laupattarakasem W, Kaen K. Musculoskeletal melioidosis. J Bone Joint Surg Am. 1993; 75 (12), 1811-5.

[5] Wu H, Wang X, Zhou X, et al. Osteomyelitis and septic arthritis due to Burkholderia pseudomallei: A 10year retrospective melioidosis study from South China. Front Cell Infect Microbiol. 2021; 11, 654745.

[6] Zueter AM, Abumarzouq M, Yusof MI, Wan Ismail WF, Harun A. Osteoarticular and soft-tissue melioidosis in Malaysia: clinical characteristics and molecular typing of the causative agent. I Infect Dev Ctries. 2017; 11 (1), 28-33. [7] Vidyalakshmi K, Lipika S, Vishal S, Damodar S,
Chakrapani M. Emerging clinico-epidemiological trends in melioidosis: analysis of 95 cases from western coastal India. Int J Infect Dis. 2012; 16 (7), e491-7.

[8] Teparrukkul P, Nilsakul J, Dunachie S, Limmathurotsakul D. Clinical epidemiology of septic arthritis caused by Burkholderia pseudomallei and other bacterial pathogens in Northeast Thailand. Am J Trop Med Hyg. 2017; 97 (6), 1695-701.

[9] Shetty RP, Mathew M, Smith J, Morse LP, Mehta JA, Currie BJ. Management of melioidosis osteomyelitis and septic arthritis. Bone Jt J. 2015; 97-B (2), 277-82.

[10] Raja NS, Scarsbrook C. Burkholderia pseudomallei causing bone and joint infections: a clinical update. Infect Dis Ther. 2016; 5 (1), 17-29.

[11] Kosuwon W, Taimglang T, Sirichativapee W, Jeeravipoolvarn P. Melioidotic septic arthritis and its risk factors. J Bone Joint Surg Am. 2003; 85 (6), 1058-61.

[12] Morse LP, Smith J, Mehta J, Ward L, Cheng AC, Currie BJ. Osteomyelitis and septic arthritis from infection with Burkholderia pseudomallei: A 20-year prospective melioidosis study from northern Australia. J Orthop. $201 ; 10$ (2), 86-91. 